\title{
Situation Analysis and Strategic Development of Fresh food E-commerce in China
}

\author{
Juxiang Zhang \\ (Tan Kah Kee College, Xiamen University, ZhangZhou, China) \\ 14827686@qq.com
}

\begin{abstract}
Keywords: Fresh food E-commerce; Business model; Development strategy; China
Abstract. In China, fresh food E-commerce is in the exploration stage and develops rapidly in recent years. This paper introduces four fresh food E-commerce models, then discusses problems and analyzes the external political and economic environment. Development strategies are put forward from the macroscopic and microcosmic view. Government should improve supporting policies and increase investment in agricultural research. E-commerce enterprises can use Pre-sale mode, standardized production, crowdsourcing Model, customized service and other methods to further develop.
\end{abstract}

\section{Introduction}

As daily necessities, fresh food has a huge market. Since its current online shopping penetration rate is only $1 \%$, compared to $10 \%$ of online retail business, fresh food is considered as a blue ocean in the E-commerce field in China. ${ }^{[1]}$ Therefore, fresh food becomes a hot spot chasing by Chinese E-business enterprise in recent years. Quite a few large online shopping malls began to build fresh food channel, trying to meet consumer demands and facing many difficulties and challenges in the seemingly bright sales prospects.

\section{Relevant concepts}

Broadly fresh food refers to primary products without cooking and other deep-processing procedure, selling via necessary preservation and simple preparation for the shelves, as well as bread, cooked food and other on-site processing of commodity categories. Features and storage conditions of fresh goods are substantially the same. They all need fresh-keeping, chilling or freezing, belong to bulk commodities sold by weighing with barcode, and have relatively short shelf life. In this study, fresh food includes fresh fruit, vegetables, meat, seafood, baking cakes, dairy and gees. Fresh food E-commerce refers to transaction via internet platform, directly distributing fresh products to consumers by self-built logistics or through third-party logistics. B2B transactions of fresh category are not covered in this study.

\section{Status of Fresh food E-commerce}

General situation. In China, fresh food E-commerce has experienced 10 years of development. As early as 2005, Yiguo network began the fresh food online selling in domestic market; in 2009, Shanghai Hoda network formally launched specially for expatriates; in 2010, Tootoo network and Yoocai network started operations, as well as the subsequent emergence of Dolly farm and Youguo network.

Owing to the immature market conditions, little big-size E-business platform enter this field, which limits the market coverage area of fresh food E-commerce. However, with the further development of online shopping, fields of books, 3C, department stores and etc have entered the fierce competition stage. Only fresh products have the potential and opportunities for development, hence many E-commerce companies take this as a breakthrough.

In 2011, COFCO's Womai network began to get involved in the fresh products. In 2012, Tmall network, Shop No. 1 network and Jingdong Online Store opened fresh channels, representing the 
comprehensive E-business website began to exploit fresh food market. In 2014, semi-finished fresh food $\mathrm{O} 2 \mathrm{O}$ business emerged in increasing numbers.

In 2011, COFCO's Womai network began to get involved in the fresh products. In 2012, Tmall network, Shop No. 1 network and Jingdong Online Store opened fresh channels, representing the comprehensive E-business website began to exploit fresh food market. In 2014, semi-finished fresh food $\mathrm{O} 2 \mathrm{O}$ business emerged in increasing numbers.

Fresh business enterprise types. According to the difference of business model, the industry of fresh food E-commerce is classified into five types, which are vertical type, comprehensive type, platform-based type, new farmer type, and semi-finished fresh food $\mathrm{O} 2 \mathrm{O}$ type.

Vertical B2C electric business enterprise. Retailers only provide consumers with fresh produce through self-built e-commerce website. Product positioning is generally relatively high-end, and web traffic and stable site users are limited. With its own logistics, most of retailers have their own farm. They need to bear pressure of the fixed costs of cold chain logistics and farm investment.

The typical enterprise is Tootoo. This company established online business in 2008, mainly engaged in high-end organic vegetables, fruits, aquatic products and meat. The cold chain distribution reached 32 cities, including its own logistics in Beijing and cooperation in other cities. It has 1050 acres organic farms in line with EU standards certified in Beijing.

Comprehensive B2C electric business enterprise. Retailers provide consumers various types of products, including fresh agricultural products through self-built e-commerce sites. They have high web traffic and a large number of registered users, and have their own logistics without their own farm. They don't need to pay the additional website construction cost of fresh business, but need to withstand the pressure of cold chain logistics investment. Usually they have good reputation and payment methods are diverse and flexible.

The typical enterprise is Shop No. 1. The company's fresh food on-line business started in 2013, and it mainly sells organic food and imported products including fruits, vegetables, meat and aquatic products. Its own cold chain distribution range from Shanghai, Beijing to Guangzhou and is gradually expanding.

Platform-based B2C electric business enterprise. Such enterprise is essentially an intermediary that provides a trading platform for fresh food producers and middlemen to serve consumers. It is characterized by providing convenient, safe and diverse trading environment, which itself is not responsible for product distribution and after-sales service. The main cost is the construction and maintenance cost of e-commerce platform.

The typical enterprise is the Taobao network. According to "2015 White Paper on E-commerce of agricultural Ali" compiled by Ali Institute the statistics, Taobao (including Tmall) fresh produce sales in 2015 increased by $63.8 \%$ compared with 2014, ranked the second place among the growth rates of agricultural products. ${ }^{[6]}$

New-farmer B2C electric business enterprise. Strictly speaking, New-farmer fresh business enterprises are not totally enterprises in the legal sense, because quite a few are individuals in which some are directly engaged in agricultural production activities and some are cooperated with agricultural producers. Their business is related to fresh agricultural products. They sell fresh produce through third-party platform, usually relying on platform-based B2C electric business enterprise. They don't have their own e-commerce website and logistics. In practice, these operators have to carry on the operation of enterprise even if they are not registered.

Semi-finished fresh food $\mathbf{O 2 O}$ enterprise. Retailers provide semi-finished fresh food for consumers demanding convenient, nutritious and healthy food through self-built e-commerce website. Customers receive already cut, cleaned semi-finished products with spice packet and cooking guide. These enterprises cooperate with community convenience stores and put freezers there. Customers are able to experience products on-site before online purchase, and goods will be distributed or packed up by customers themselves from convenience stores. ${ }^{[2]}$ In addition to on-site experience, consumers can benefit from other support services, such as sales return, commodity consulting and etc. The typical enterprises are Mr.Food, Xinwei and Mian. 


\section{External environment}

All along, Chinese government attaches importance to agricultural development, emphasizes agricultural modernization and technology development in No.1 Central Documents for many years. For example, in 2014 No.1 Central Document proposed to strengthen the construction of agricultural e-commerce platform; in 2015, the No.1 Central Document again referred innovation of agricultural products circulation patterns and support enterprises involved in agriculture related business platform construction. During the period of March 2015 NPC and CPPCC, the government work report first mentioned the "Internet +" program, encourages all industries to combine with internet technology, which brought development opportunities for fresh products e-commerce. In addition, in recent years both the national and local Development and Reform Commission introduced development plans of agricultural cold chain logistics in succession. Overall, documents concerning agricultural e-commerce and development planning of cold chain logistics provide a strong policy support for fresh good E-business.

According to the data of National Bureau of statistics, China's agricultural output grew steadily in recent years, as shown in Fig.1. In 2014, China's total grain output reached 6.07 million tons, increase $0.85 \%$ over the previous yea $\mathrm{r}$; the output of fruit, meat, milk and eggs are 2.6 million tons, 8706.7 million tons, 3724.6 million tons, 2893.9 million tons respectively; except milk, the amount of other crops all rose compared with last year. ${ }^{[7]}$

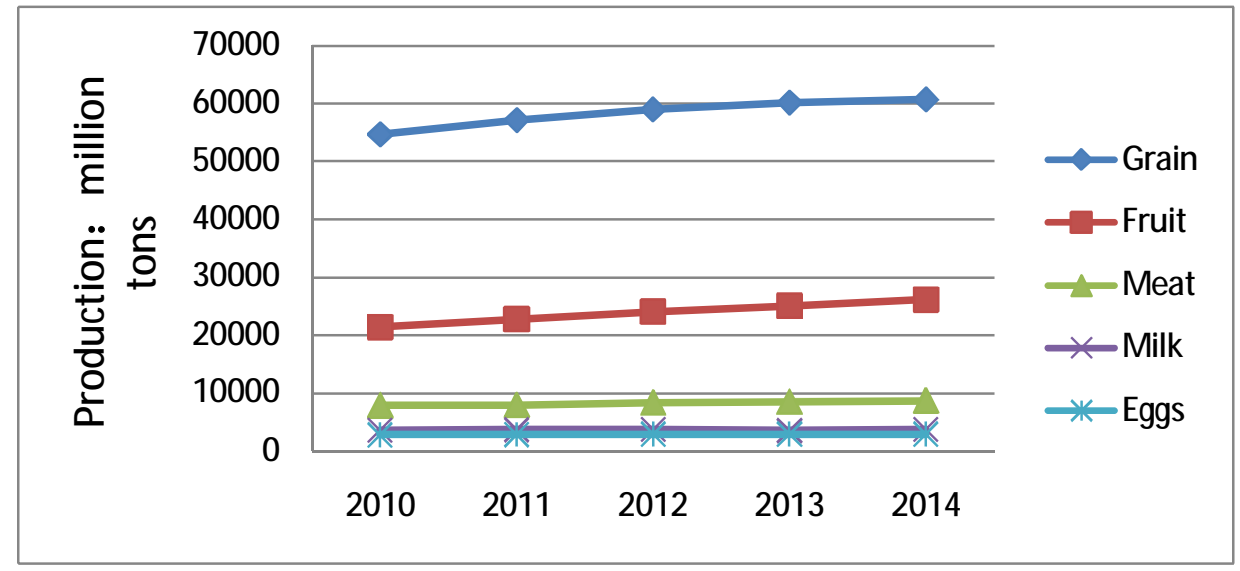

Fig.1. 2010-2014 Output of major agricultural products in China

Owing to food safety problems in China, such as tonyred egg, Sanlu poisonous milk powder and swill-cooked dirty oil, public confidence in food safety exists crisis. In this situation, the consumer awareness of food safety is getting higher and higher, more and more attention is paid to the origin and source of food. Online retailers mainly sell fresh products directly from the place of origin, shorten the intermediate links, make product information more transparent, and thus meet the needs of consumers to a certain extent.

In these years, the domestic urban residents' per capita disposable income and net income of rural residents continued to improve, and the Engel coefficient of urban and rural residents declined continuously, as shown in Fig.2. While the quality of life upgrading, demands of residents on food safety, freshness, convenience increase as well, and the development of E-business just can effectively address these needs. 


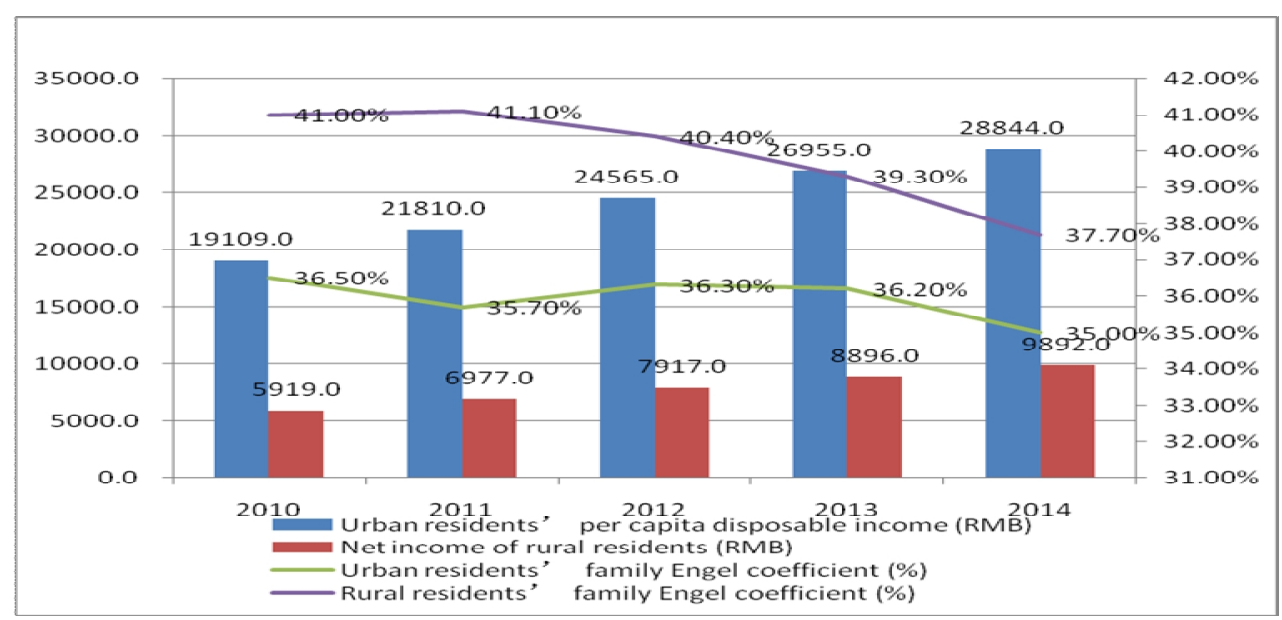

Fig.2. 2010-2014 Chinese urban and rural residents' per capita disposable income and family Engel coefficient

At the same time, domestic Internet penetration rate gradually goes up, mainly because of the continued growth of Internet users and mobile Internet users, as shown in Fig.3. High Internet penetration rate has laid a solid customer foundation for fresh food suppliers. Besides, Mobile Internet technology makes the fresh business more efficient. Big data technology can help companies understand user needs more accurately and improve service quality.

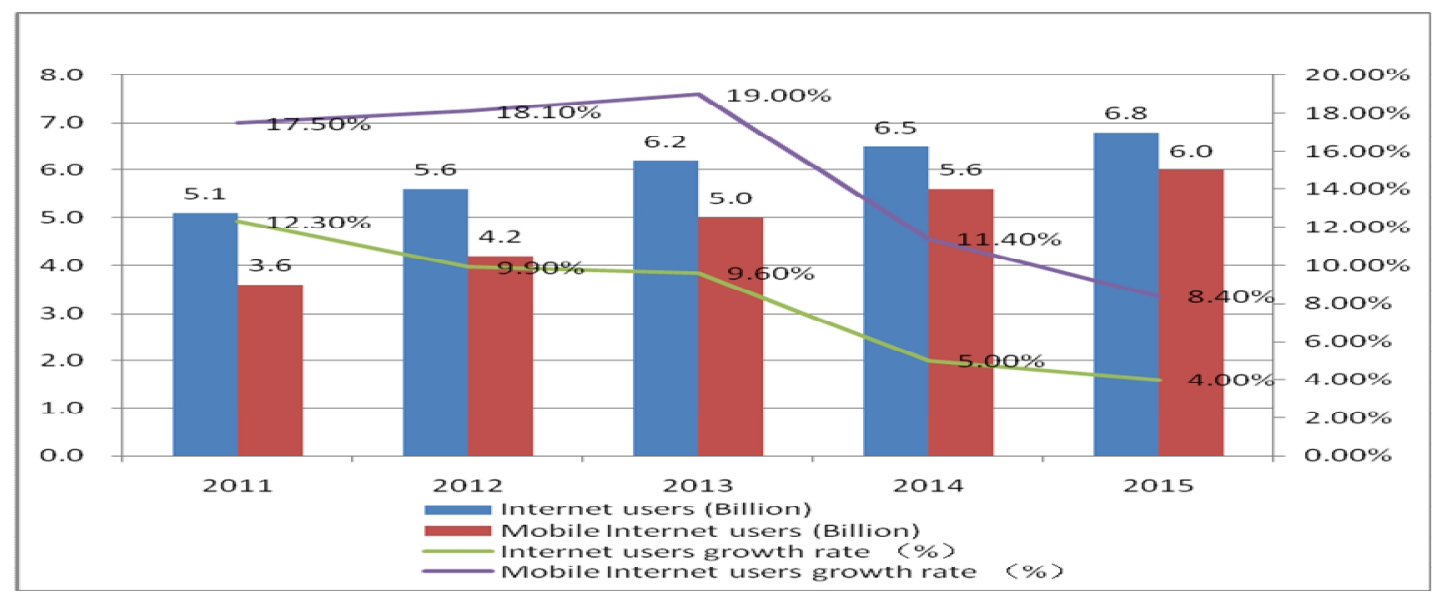

Fig.3. 2011-2015 China's overall Internet users and mobile Internet users

\section{Problems of fresh food E-commerce}

Large product loss. Fresh products from suppliers to consumers mainly experience three period, namely warehousing, transportation and delivery. Due to the short freshness lifetime fresh food will be spoiled easily if it is not timely sales, which resulted in large inventory loss.

After the customer places an order, fresh products in the distribution process is also prone to loss. First of all, road bumps lead to product loss; secondly, the improper handling behaviors cause product loss, such as lying roughly. If the customer is not just at home, next day delivery will lead to greater loss of fresh products. According to industry statistics, the loss rate of fresh food is about $10 \% \sim 30 \%{ }^{[3]}$

High distribution cost. Fresh products have special requirements in warehousing and in logistics compared with normal temperature commodity; therefore fresh food E-business companies distribute goods throughout the cold chain transportation. According to industry statistics, in the case of cold chain outsourcing, the transportation and storage costs of refrigerated goods is 4-5 times higher than normal temperature cargo. If fresh food companies invest in cold chain, they also face high costs.

Cold chain distribution improves the product freshness, but also leads to high distribution costs. To get free delivery, Consumption amount is usually required higher than $100 \mathrm{RMB}$, which has adverse effect on purchase frequency. 
Non standardization of products. Fresh products are non-standardized products, the size, shape, quality and taste of each product is often different, even from the same origin due to different planting time.

Non standardization of fresh products has impacts in three areas. Firstly, there is a gap between the picture and the real. While customers browsing websites, brightly colored fresh products with uniform size are seen. However the goods received are uneven size even in gloomy color. Secondly, non-standardization is not conducive to unified packaging and distribution. Thirdly, non-standardization reduces consumer loyalty. Different batches of fresh products usually taste difference, although the appearance is the same, which affects the consumer recognition and loyalty. ${ }^{[4]}$

Weak user experience. Although a small part of E-commerce enterprises try to use the $\mathrm{O} 2 \mathrm{O}$ model, but offline experience is still in the initial stage with low user engagement. Most E-commerce enterprises focus resources on user browsing, online promotion and back-stage management, offline experience is not highly concerned, and thus, a unique tactile and visual experience of products and shops cannot be delivered like the traditional fresh store.

\section{Development strategies for fresh food E-commerce}

Development strategies from the macroscopic view. The development of fresh food E-commerce would be considered both from the macroscopic view and the microcosmic view.

It is necessary for government to improve relevant policies so as to create a fair environment for the development of fresh food E-commerce. For example, more support policies, such as low-yielding subsidies, need to be introduced to encourage farmers; more enabling policies for logistics and overall planning of infrastructure construction need to be developed to facilitate distribution; more favorable policies need to be created to subsidize E-business companies.

Laws and regulations also need to be introduced to ensure an orderly environment. It is necessary to speed up the legislation concerning agricultural products security, to improve supervision and inspecting system for agricultural products, and to conduct tracing and undertaking mechanisms. ${ }^{[5]}$

Compared with developed countries, there is a large gap of agriculture mechanization. Increase investment in agricultural science research is necessary, such as agricultural machinery development and agricultural production technology

In addition, Electric business enterprise with its own farm often has a short board about agricultural production techniques. Take Tootoo as an example, because of lack of agricultural techniques, it picked peaches after the rain which causes rapid decay. Government could lead research institutions to guide farms by teaching practical, innovative agricultural production technology. On the other hand, scientific and technological achievements could be effectively converted to agricultural productivity.

\section{Development strategies from the microcosmic view.}

Pre-sale mode. Pre-sale mode is a good method to get rid of inventory to a large degree. Before the agricultural products ripening, E-business companies can introduce specific information about products on the website to attract orders, such as climate, soil, and product features and benefits. When agricultural products are ripe, they should be delivered to customers as fast as possible, so as to eliminate inventory or achieve zero inventory. Pre-sale mode is a demand-driven mode that makes the supply precisely match demand and decreases the inventory cost and loss rate of fresh goods.

Standardized production. E-business enterprises may entrust agricultural research institutions establish the standard of production technology and production process. Hence, agricultural products can be planted in accordance with unified standards for transformation of the soil, fertilization, harvesting, and final packaging with the unified standard as well. In this way, product differentiation could be narrowed down, and similarity of the products could be expanded. Standardized production could ensure consistent quality of the fresh products, and improve product quality and safety as much as possible, thus provide a reliable supply for E-business companies. 
Diversified distribution mode. Fresh food has a great variety products, including fruits and vegetables, aquatic products, poultry meat, processed foods, etc. During the distribution process, different categories of goods require different storage temperature, so diversified distribution methods might be used to reduce distribution cost. Frozen product, such as chilled meat, could use cold chain to realize entire temperature control; fresh-keeping products, such as fruits, could use physical cooling methods like ice; normal-temperature product, such as root vegetables, could use normal distribution methods, so as to not only meet the preservation needs but also reduce distribution cost.

Crowdsourcing Model. Crowd-sourcing Model may be adopted to enhance the distribution efficiency. Fresh food E-business enterprises could issue delivery information through the Internet or mobile apps to the public, recruit part-time delivery staff and provide compensation, or seek cooperation with communities individual resident by setting up a delivery site, thus achieving universal participation in distribution. Crowd-sourcing Model could make full use of external human resources, improve the Last Kilometer delivery efficiency, and reduce the cost of distribution. ${ }^{[3]}$

Customized service. Customized service might be provided to meet different needs. E-business enterprises could offer "customized package", provide advice of how to with reasonable and scientific dishes according to the consumer's eating scene, the number of people, consumption amount and other information. More gourmet kitchen packages, semi-finished dishes, and combined dishes are also needed to facilitate busy office workers.

Strengthen brand community stickiness. For community consumers, community activities related to food and cooking could be organized to strengthen the brand community stickiness for E-business companies. For example, holding events about cooking interaction, recipe introduction, gourmet club, and service guidelines and so on would enhance brand community stickiness, gain loyal members and promote online sales.

\section{Conclusions}

Fresh food E-commerce in China is in the exploratory stage of development, facing many problems and challenges. Government should encourage and guide the development of E-commerce, introduce relevant supporting policies, provide some financial support for E-commerce enterprises, integrate all kinds of resources to creating good development conditions for Fresh food E-commerce industry. At the same time, fresh food quality and safety testing should be totally carrying out for residents. E-commerce enterprises can use Pre-sale mode, standardized production, crowdsourcing Model, customized service and other methods to further develop.

\section{References}

[1] Jiansheng Fang, Jian Liu, Yuquan Liu: Agricultural Outlook (In Chinese) Vol.12 (2014). p75-77

[2] Haiyan Yi, Feng Zhang: Chinese Market (In Chinese) Vol.31 (2014). p26-27

[3] Hanlin Ji, Jinhua Zhou, Shen Zhang: Logistics Engineering and Management (In Chinese) Vol.38 (2016). p93-95

[4] Junshan Zhang, Qiaozhi Huang:Logistics Technology, (In Chinese) Vol.34 (2015). P30-31

[5] Meng Chu, Baoming Zhang:E-Business Journal (In Chinese) Vol.12 (2015). p13-14

[6] Information on http://www.aliresearch.com/blog/article/detail/id/20897.html

[7] Information on http://data.stats.gov.cn/easyquery.htm?cn=C01\&zb=A0D0G\&sj=2014 